University of Nebraska - Lincoln

DigitalCommons@University of Nebraska - Lincoln

2014

\title{
Temperature, Hatch Date, and Prey Availability Influence Age-0 Yellow Perch Growth and Survival
}

\author{
Mark A. Kaemingk \\ University of Nebraska - Lincoln, mkaemingk2@unl.edu \\ Brian D. S. Graeb \\ South Dakota State University, Brian.Graeb@sdstate.edu \\ David W. Willis \\ South Dakota State University
}

Follow this and additional works at: https://digitalcommons.unl.edu/natrespapers

Part of the Natural Resources and Conservation Commons, Natural Resources Management and Policy Commons, and the Other Environmental Sciences Commons

Kaemingk, Mark A.; Graeb, Brian D. S.; and Willis, David W., "Temperature, Hatch Date, and Prey Availability Influence Age-0 Yellow Perch Growth and Survival" (2014). Papers in Natural Resources. 688.

https://digitalcommons.unl.edu/natrespapers/688

This Article is brought to you for free and open access by the Natural Resources, School of at DigitalCommons@University of Nebraska - Lincoln. It has been accepted for inclusion in Papers in Natural Resources by an authorized administrator of DigitalCommons@University of Nebraska - Lincoln. 


\title{
Temperature, Hatch Date, and Prey Availability Influence Age-0 Yellow Perch Growth and Survival
}

\author{
Mark A. Kaemingk, Brian D. S. Graeb, and David W. Willis \\ Department of Natural Resource Management, South Dakota State University, \\ Box 2140B, Brookings, South Dakota 57007, USA \\ Corresponding author — Mark Kaemingk
}

\begin{abstract}
Throughout their range, Yellow Perch Perca flavescens are an important ecological and economic component of many fisheries, but they often exhibit highly variable recruitment. Much research effort has been devoted to better understanding the mechanisms responsible for these erratic recruitment patterns, yet few studies have examined this process at the detail necessary to reveal complex interactions that may exist across multiple early life stages. Our current understanding of the early life recruitment patterns of Yellow Perch suggests a strong abiotic component. Using existing information, we developed three working hypotheses to examine Yellow Perch recruitment at two larval stages (5-14 and 15-24 d old) and to further identify the overarching mechanisms (abiotic versus biotic) related to Yellow Perch recruitment in 332-ha Pelican Lake, Nebraska, during 2004-2012. Larval Yellow Perch growth and mortality were largely regulated by hatching date, temperature, and zooplankton availability. The growth of young larval Yellow Perch (5-14 d old) was positively related to temperature and hatch date; that of old larval perch (15-24 d old) was positively related to water temperature and postlarval age-0 ( $\leq 25 \mathrm{~mm}$ TL) Yellow Perch density but negatively related to the available preferred zooplankton biomass. Mortality was inversely related to total zooplankton biomass and water temperature. Our results describe a model with two potential Yellow Perch recruitment bottlenecks, one immediately posthatch that is regulated by hatch date and temperature and another during the older larval stage that is regulated by temperature and zooplankton.
\end{abstract}


Understanding the mechanisms involved in determining fish recruitment or year-class strength has long been a challenge in fisheries science. Although much progress has been made to isolate these mechanisms, many studies are site specific or species specific or both (Claramunt and Wahl 2000). Yearclass strength is often determined during the early life stages in fish (Rice et al. 1987) due to the low percentage $(<1 \%)$ of fish that survive past this stage (Chambers and Trippel 1997). Despite much effort to identify overall patterns in recruitment within a species, few consistent patterns typically emerge. In some cases, patterns may be detected but are weak and typically provide little information of proximate or ultimate mechanisms relating to recruitment. Thus, broad landscape-type studies can provide insight as to which factors may be involved in the recruitment process, but they lack the resolution to identify when and how they are affecting the population.

Recruitment is most likely driven by a combination of the abiotic and biotic factors experienced at each stage of life, complicating the process of determining which factors are most responsible for structuring fish communities via recruitment. Interannual differences also mask patterns related to recruitment in fish populations, and those differences are difficult to detect with many statistical approaches. As a result, more information on the ultimate mechanisms limiting fish recruitment is imperative during the critical early life period, and more long-term in-depth studies are needed to acquire such information. Better understanding of processes involved in regulating first-year survival would provide managers the capability of predicting yearclass strength and allow them to initiate management efforts, such as adjusting angling regulations or stocking in years of expected low recruitment.

The recruitment of Yellow Perch Perca flavescens has been of importance to fisheries biologists due to the species' ecological value as prey for other species of fish and its economic importance as a highly sought after sport fish. Yellow Perch recruitment is often highly variable in many systems and is typified by strong, weak, or missing year-classes (Koonce et al. 1977; Newsome and Aalto 1987; Isermann et al. 2007). It is difficult to predict which years will result in a strong year-class without understanding essential mechanisms driving Yellow Perch recruitment. Recruitment variability in Yellow Perch has been explained predominantly by abiotic factors during early life stages. This recruitment pattern is most likely because Yellow Perch spawning typically occurs over a 5-11-d period (Isermann and Willis 2008); thus, eggs and young larvae could be subject to variable environmental conditions. These conditions include variations in wind, precipitation, and temperature (Clady and Hutchinson 1975; Clady 1976; Kallemeyn 1987; Pope et al. 1996;Ward et al. 2004). High winds have the potential to sweep egg masses onto shore resulting in egg damage and potentially lower survival (Clady and Hutchinson 1975). Improved larval survival has been related to years when spring temperatures are warmer and winds are less intense 
(Clady 1976). In addition, recruitment may be enhanced in years with less variation in temperature and increased precipitation (Pope et al. 1996). Thus, temperature, wind, and precipitation appear to influence Yellow Perch recruitment, but relative impacts by each variable may differ among water bodies (Ward et al. 2004).

The interannual variation in larval Yellow Perch abundance is often not fully explained by climatological information across multiple systems or years at a coarse resolution (Pope et al. 1996; Ward et al. 2004; Longhenry et al. 2010), which suggests the need to also consider biological mechanisms as potential limiting factors for recruitment. For example, prey availability and composition could also influence growth and survival during the larval stage. In systems predominated by cladocerans (as opposed to copepods), the increased handling time and lower digestive efficiencies associated with cladocerans could result in slower growth and ultimately lower survival of Yellow Perch less than $12 \mathrm{~mm}$ TL (Graeb et al. 2004). However, larval Yellow Perch growth and survival may increase during periods of high copepod densities (Graeb et al. 2004). Differences in zooplankton community composition across systems can influence diet selection and survival of Yellow Perch, even in the context of equal total zooplankton density (Fulford et al. 2006). Larval Yellow Perch may also be gape-limited initially after hatching, allowing only smaller zooplankton to be consumed (Bremigan et al. 2003). However, most of the current evidence for biotic regulation of Yellow Perch recruitment at the larval stage has been obtained from laboratory or controlled experiments, extending the need to test these hypotheses with longterm, in-depth field studies.

Our current understanding of larval Yellow Perch recruitment identifies more abiotic than biotic factors, but the level of influence (e.g., strong or weak) for each may depend on the life stage examined and could be system specific (nullifying an attempt to reveal any unifying themes). Using existing studies, we developed three working hypotheses to (1) examine Yellow Perch survival patterns at two larval life stages: "young larvae" (5-14 d old) and "old larvae" (15-24 d old) and (2) identify the overarching mechanisms (abiotic versus biotic) related to their recruitment. We tested those hypotheses in Pelican Lake, Nebraska, via 9 years of sampling from 2004 to 2012. First, we hypothesized that the magnitude of influence for abiotic and biotic factors on larval Yellow Perch growth would differ between the young and old larval life stages, young larvae being regulated more by abiotic than biotic factors and the inverse being true for old larvae. Second, we expected larval Yellow Perch survival to primarily be related to abiotic factors. Finally, we anticipated that the overall recruitment of Yellow Perch from the larval to juvenile life stages would be largely influenced by abiotic factors rather than biotic factors. 


\section{Methods}

Study area.-Pelican Lake is a 332-ha, shallow (mean depth $=1.3 \mathrm{~m}$ ) natural lake in the Sandhills region of northcentral Nebraska within the Valentine National Wildlife Refuge ( $\left.42^{\circ} 31^{\prime} 37^{\prime \prime} \mathrm{N}, 100^{\circ} 40^{\prime} 20^{\prime \prime} \mathrm{W}\right)$. Aquatic emergent vascular plant coverage, determined in late July 2009 via the methods of Paukert et al. (2002), was $8.5 \%$ for reeds Phragmites spp., $15.5 \%$ for bulrushes Scirpus spp., and $7.0 \%$ for cattails Typha spp. The remaining portion of the lake was classified as submersed vegetation (9.9\%) and open water (59.1\%) devoid of vegetation (Kaemingk and Willis 2012). The fish assemblage is composed primarily of Bluegill Lepomis macrochirus, Yellow Perch, Largemouth Bass Micropterus salmoides, Northern Pike Esox lucius, Black Bullhead Ameiurus melas, Common Carp Cyprinus carpio, and Fathead Minnow Pimephales promelas.

Larval and postlarval age-0 sampling and aging.-Larval ( $<13 \mathrm{~mm} \mathrm{TL})$ and postlarval age-0 ( $\leq 25 \mathrm{~mm} \mathrm{TL}$ ) Yellow Perch length groups were defined and sampled every $10 \mathrm{~d}$ from April through June 2004-2012 during daylight hours. Larval and postlarval age-0 Yellow Perch densities were indexed using a surface trawl with a $0.76-\mathrm{m}$ opening and 1-mm mesh (bar measure) towed in large ellipses. Trawl duration was approximately 2-5 min at an estimated speed of $1.75 \mathrm{~m} / \mathrm{s}$. The lake was divided into 16 quadrats; 10 quadrats were randomly selected and trawled on each occasion. The amount of water volume sampled was calculated using a flowmeter (Ocean Test Equipment, Inc.) mounted in the mouth of the trawl. All fishes were preserved in $70 \%$ ethanol and transported to the laboratory for identification to species (Auer 1982; Holland-Bartels et al. 1990), enumerated, and up to 200 randomly selected fish of each species per sample were measured ( $T L ; \mathrm{mm})$.

We collected, measured ( $\mathrm{TL} ; \mathrm{mm}$ ), and aged a minimum of 30 larval Yellow Perch (or three from each quadrat sampled) from each sampling date each year (except when fewer than 30 larval Yellow Perch were collected). Aged larvae were randomly selected and closely mirrored the size structure of the larger sample for each sampling date. Four separate $10-d$ hatching cohorts (cohort $1=$ April 14-23, cohort $2=$ April 24 to May 3, cohort $3=$ May 4-14, and cohort 4 = May 15-23) were developed that accounted for all larval Yellow Perch aged during 2004 through 2012. During any given year, not all 10-d hatching cohorts were represented due to differences in interannual hatching phenology. Sagittal otoliths of larval Yellow Perch were aged by two independent readers using a compound microscope, and daily age estimates were averaged if they were within $10 \%$ of each other (Santucci and Wahl 2003). A third experienced reader was consulted if there was no agreement between readers, and the otolith was read in concert until consensus was reached. If all readers failed to reach an agreement the otolith was removed from the data set ( $9 \%$ were removed). 
Independent variable field sampling.-To explain the patterns in Yellow Perch growth and mortality, independent variables encompassing four broad categories were sampled and used: physical (Ward et al. 2004), competition (Post and Prankevicius 1987; Irwin et al. 2009), food availability (Mills et al. 1989), and intrinsic (i.e., of or relating to processes within Yellow Perch larvae; Isermann and Willis 2008; Table 1). Independent variables were selected based on previous studies relating to Yellow Perch growth and mortality during the first year of life. Unless otherwise noted, samples for each independent variable were collected every $10 \mathrm{~d}$ from April to June from 10 (of 16 available) randomly selected lake quadrats during 2004-2008 and five quadrats during 2009-2012 (Kaemingk et al. 2011, 2012).

We quantified phytoplankton biomass for each quadrat using chlorophyll $a$ estimated from integrated water samples (two/quadrat) that were collected using a 2-m-long tube sampler. Samples were strained through glass microfiber filters $(1 \mu \mathrm{m})$ in the field and extracted in the laboratory following the methods described by Lind (1985). Temperature data were recorded hourly with a HOBO pendant data logger (Onset Computer Corporation, Bourne, Massachusetts 02532) placed near the bottom of the lake (Pelican Lake and other Sandhill lakes are very shallow and do not thermally stratify; McCarraher 1964). Water transparency was measured using a Secchi disk at each quadrat sampled.

Zooplankton were collected using the same 2-m-long tube sampler to sample phytoplankton (Rabeni 1996). Two zooplankton samples were collected at each quadrat and filtered through a 65- $\mu \mathrm{mmesh}$ net, stored in

Table 1. Candidate variables used to predict young (5-14 $d$ old) and old (15-24 d old) larval Yellow Perch growth (GR) and survival (SU).

\begin{tabular}{|c|c|c|}
\hline $\begin{array}{l}\text { Candidate } \\
\text { independent variable }\end{array}$ & Description & $\begin{array}{l}\text { Response } \\
\text { variable(s) }\end{array}$ \\
\hline \multicolumn{3}{|l|}{ Physical } \\
\hline 1. Water transparency (WT) & Mean Secchi disk reading of $10-d$ intervals & $\mathrm{GR}, \mathrm{SU}$ \\
\hline 2. Temperature (TP) & Mean daily water temperature & GR, SU \\
\hline 3. Phytoplankton (PHYT) & Mean chlorophyll- $a$ density of $10-d$ intervals & GR, SU \\
\hline \multicolumn{3}{|l|}{ Competition } \\
\hline 1. Larval intraspecific (YEPL) & Mean 10-d trawling density of Yellow Perch $<13 \mathrm{~mm}$ & TL GR, SU \\
\hline 2. Age-0 intraspecific (YEPA) & Mean 10 - $d$ trawling density of Yellow Perch $\leq 25 \mathrm{~mm}$ & TL GR, SU \\
\hline \multicolumn{3}{|l|}{ Food availability } \\
\hline 1. Total zooplankton (TZP) & $\begin{array}{l}\text { Mean biomass of appropriately sized zooplankters } \\
\text { during } 10-d \text { intervals }\end{array}$ & GR, SU \\
\hline 2. Preferred zooplankton (PZP) & $\begin{array}{l}\text { Mean biomass of appropriately sized cyclopoid copepods } \\
\text { during 10-d intervals (Jolley et al. 2010) }\end{array}$ & GR, SU \\
\hline \multicolumn{3}{|l|}{ Intrinsic } \\
\hline 1. Larval growth rate $(G R)$ & Young or old larval Yellow Perch daily growth rates & SU \\
\hline 2. Hatch date $(\mathrm{HD})$ & Mean hatch date of 10-d larval cohorts & GR, SU \\
\hline
\end{tabular}


90\% ethanol, and then processed separately. Zooplankton were enumerated and identified to genus, cladocerans being Bosmina, Ceriodaphnia, Chydorus, Daphnia and copepods being Cyclops, and Diaptomus, as well as copepod nauplii. Each sample was diluted with water to a measured volume of $30 \mathrm{~mL}$. Three subsamples were taken with a 5-mL Hensen-Stempel pipette and placed in a Ward counting wheel. Zooplankters were enumerated within each subsample, and the total number of zooplankton of each taxon in a sample was calculated by dividing the number of organisms counted by the proportion of the sample volume processed. Density was calculated by dividing the number of zooplankters of each taxon by the volume of the water filtered with the tube sampler. Up to 20 individuals per taxon were measured ( $\mathrm{TL} ; 0.01 \mathrm{~mm}$ ) from each sample, and taxon-specific, length-dryweight conversions were used to convert length to biomass ( $\mu$; Cummins and Wuycheck 1971; Dumont et al. 1979; McCauley and Kalff 1981; Culver et al. 1985; Lynch et al. 1986).

Analyses of growth and mortality rate.-Daily growth rates for larval Yellow Perch $(\mathrm{mm} / \mathrm{d})$ were estimated as $(T L-4.7) /$ age, where $T L$ is the length $(\mathrm{mm})$ at capture, 4.7 is the total length at hatch $(\mathrm{mm}$; Heidinger and Kayes 1993; Kaemingk, unpublished data), and age represents the age (d) posthatch. Powles and Warlen (1988) reported that the first growth increment occurred at 1-3 d posthatch for Yellow Perch, but most larvae exhibited initial growth increments $1 \mathrm{~d}$ posthatch in that study. Therefore, hatching date for individual Yellow Perch was calculated by adding $1 \mathrm{~d}$ to the growth increment count (Isermann and Willis 2008). Two separate age-classes (young and old larvae) were defined to examine the effects of independent variables on growth because the factors influencing growth rate may differ as a function of age and size. Both young (5-14 d old) and old larvae (15-24 d old) were $<13 \mathrm{~mm}$ TL. Larval Yellow Perch were then grouped and mean growth rates were calculated according to year (2004-2012), date of collection (about 10-d intervals), hatching cohort (1-4), and age-class (young or old). A minimum of three individuals were required for each grouping for subsequent analyses (Kaemingk et al. 2014). These groupings allowed growth to be examined for larval fishes that experienced similar lake conditions and thus allow further examination of factors (independent variables) that could explain growth patterns of young (endogenous-exogenous transitional feeding stage) and old larval Yellow Perch (Bunnell et al. 2003). Analysis of covariance (Proc GLM, SAS Institute, Inc. 2003) was used to determine differences in growth rates across years for young or old larvae by examining how mean length varied as a function of age (covariate). The ANCOVA provided a more meaningful comparison of growth rates because it allowed multiple sizes of fish to be evaluated across cohorts despite potential differences in cohort mean lengths, as opposed to using growth rates that do 
not account for such differences. Post hoc year-wise comparisons were assessed using Tukey's Studentized range test. Significance for all analyses was set at $\alpha=0.10$ to guard against committing a type II error.

Larval Yellow Perch cohort hatching distributions were based on the subsample of 30 larval fish aged each sampling date and extrapolated to account for all fish sampled. Therefore, larval cohort hatching distributions were corrected $\left(H_{i}\right)$ for each sampling date using the following formula (Kaemingk et al. 2014): $H_{i}=\left(N_{i} / T\right) \times A$, where $i$ represents the 10-d hatching cohort (1-4), $N$ represents the total number of perch aged in cohort $i, T$ represents the total number of perch aged, and $A$ refers to the total number of Yellow Perch sampled. Mortality $(Z)$ was estimated for each year using catch-curve analysis and represents the rate (i.e., slope) of decline in fish abundance over time (Ricker 1975). We were unable to estimate mortality for each age-class due to insufficient sample sizes. Therefore, young and old larvae (across ages 8-21 d) were pooled to estimate mortality. Larval perch were typically (with the exception of 2005; Jolley et al. 2010) collected on multiple consecutive sampling occasions each year resulting in a bell-shaped larval abundance distribution (Jolley et al. 2010), presumably from differences in egg hatching rates and larvae entering the limnetic zone followed by larval mortality or gear avoidance. A single sampling date was selected prior to or during peak hatching dates. The larval period can be short (in some years only a few weeks) and by selecting dates near peak hatching it allowed adequate numbers of fish to be included in the analysis while also minimizing other factors that may influence accurate mortality estimates (e.g., gear avoidance related to size, littoral habitat shift). Natural mortality rates were then calculated by regressing the natural logarithm of larval Yellow Perch abundances against 1-d age classes each year. The descending limb of the catch curve was used for all analyses. Mortality of larval perch was evaluated across years using an ANCOVA (Proc Reg, SAS Institute, Inc. 2003). Post hoc year-wise comparisons were assessed using Tukey's Studentized range test.

The independent variables used to explain growth and mortality patterns were selected from four broad categories (i.e., physical, competition, food availability, and intrinsic) and transformed when necessary to meet the assumptions required for each statistical analysis. Physical variables included water transparency, temperature, and phytoplankton (Table 1). Competition variables included metrics relating to intraspecific competition for two size-classes of Yellow Perch in Pelican Lake (Table 1). Two size-classes (larval and postlarval age-0) were evaluated for Yellow Perch because densities typically declined after $13 \mathrm{~mm}$ TL (suggesting either movement toward littoral habitats or mortality. However, postlarval age-0 perch were still captured at sizes $\leq 25 \mathrm{~mm}$ TL with the larval trawl, and these fish still consumed zooplankton (Jolley et al. 2010); thus, zooplankton availability may influence 
larval growth and survival (Kaemingk et al. 2012). Food availability metrics included total zooplankton biomass that would be available for each ageclass, adjusted for gape size $(G)$ using the following formula (Schael et al. 1991): $G=-0.597+0.159(T L)$, where length and gape are in millimeters. Therefore, all available zooplankton biomass $\left(B_{\alpha^{\prime}} \mu \mathrm{g} / \mathrm{L}\right)$ within the gape size for each age-class was included in all analyses using the following formula (Bunnell et al. 2003): $B_{a}=\sum p_{i}\left(A_{i}\right)\left(B_{i}\right)$, where $p_{i}$ is the proportion of zooplankters in taxon $i$ that are $\leq G$ of larvae, $A_{i}$ refers to the total zooplankton abundance (number/L) for taxon $i$, and $B_{i}$ is the mean calculated biomass of zooplankters in taxon $i$ that are $\leq G$ of larvae. Therefore, zooplankton samples (i.e., biomass) collected during different stages and sizes of larval development could be adjusted appropriately for only available zooplankton biomass that could be readily consumed (i.e., not gape limited) by each larval age-class (Bunnell et al. 2003). Similarly, preferred available zooplankton biomass consisting of appropriately sized cyclopoid copepods was also included for each age-class growth analysis (Bunnell et al. 2003; Graeb et al. 2004; Jolley et al. 2010). Mean day of year hatch date was included as an intrinsic factor to explain growth and mortality rates, but larval growth rate (age-dependent) was solely related to mortality rate (Table 1).

Measurements of each independent variable were averaged for each cohort and related to growth and mortality rates across sampling dates that corresponded to the duration each age-class of larval Yellow Perch experienced in the lake from hatch date until capture date. For example, independent variables were typically averaged across three sampling dates for young larvae and four dates for old larvae. An information-theoretic approach (Akaike's information criterion, AIC $_{c^{\prime}}$ Burnham and Anderson 2002) was used to examine the influence of each independent variable on daily growth rates and mortality rates for larval age classes. Akaike weights indicate the relative support for a model when compared with the set of candidate models (larger weights $=$ more support). This approach allowed multiple models to be evaluated and related to larval growth and mortality rate rather than the traditional regression approach that selects only one model and ignores parsimony (Burnham and Anderson 2002). The number of available independent variables (Table 1) used to predict cohort growth and larval mortality rates was reduced following this stepwise procedure for young and old larvae: (1) only one variable was retained when multiple variables were correlated (e.g., larval perch density versus postlarval age-0 perch density), thus minimizing multicollinearity among independent variables, (2) remaining variables were related to growth and mortality rates using Pearson's product-moment correlation coefficient, and (3) the strongest relationship ( $r$ and $P$-value) between growth and mortality rate and one independent variable from each broad category (physical, competition, food availability, intrinsic) was selected for subsequent post hoc model selection (Kaemingk 
et al. 2014). Thus, candidate models included only one independent variable from each broad category (physical, competition, food availability, intrinsic), representing a range of simple and complex models $(N=14)$ used to explain growth and mortality rates. Models with delta $\operatorname{AIC}_{c}\left(\Delta_{i}\right)$ scores of $\leq 2$ were considered to provide substantial support for explaining patterns relating to larval Yellow Perch growth (Burnham and Anderson 2002). Additionally, the proportion of variance explained $\left(r^{2}\right)$ for each model was also included to evaluate each model.

\section{Results}

\section{Growth Rate}

The mean growth rates of young (5-14 d old) larval Yellow Perch ranged from 0.09 (cohort 1 of 2008) to $0.50 \mathrm{~mm} / \mathrm{d}$ (cohort 4 of 2011; Figure 1). Growth rates differed across years for young larvae (ANCOVA: $F_{9,52}=20.94$, $P<0.01)$. Growth rates were generally greater for young larvae during 2004, 2006, 2009, and 2011 than in 2005, 2007, 2008, 2010, and 2012. Old (15-24

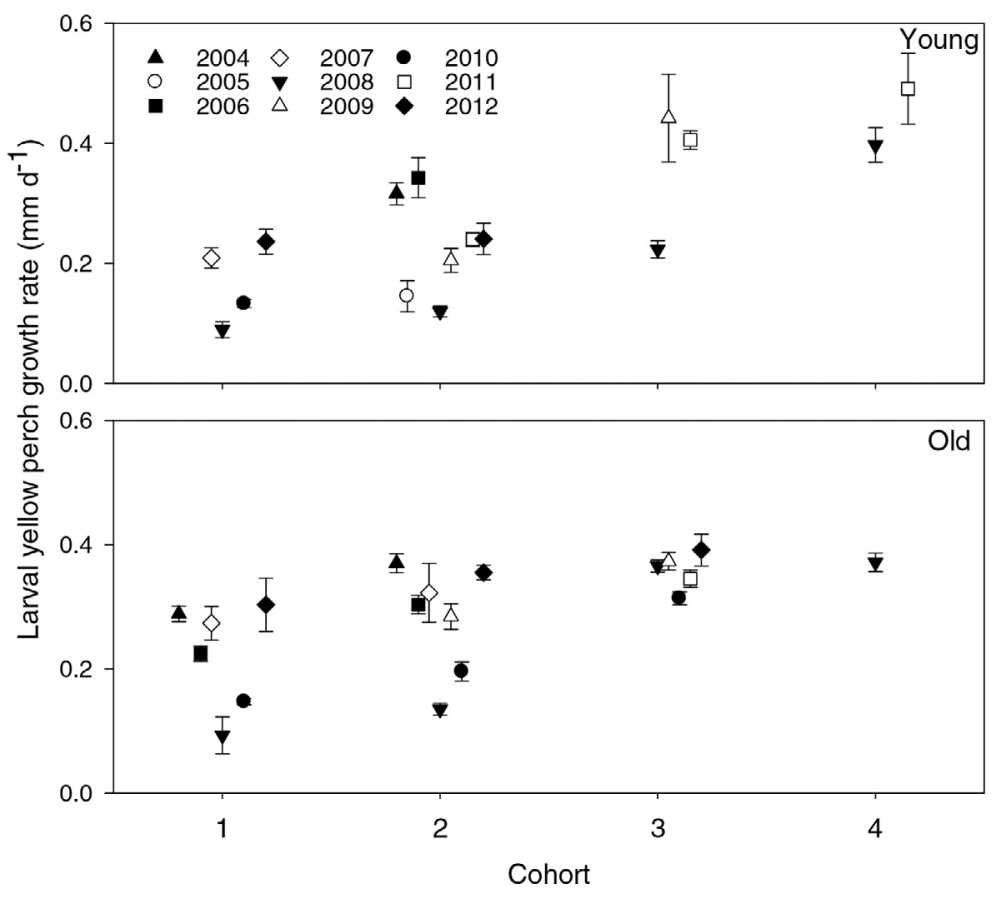

Figure 1. Mean daily growth rates for young (5-14 d old) and old (15-24 d old) larval Yellow Perch from 2004 to 2012 in Pelican Lake, Nebraska, by cohort: cohort 1 = April 14-23, cohort 2 = April 24 to May 3, cohort 3 = May 4-14, and cohort $4=$ May 15-23. Error bars represent SEs. 
d old) larval Yellow Perch growth rates ranged from 0.09 (cohort 1 of 2008) to $0.39 \mathrm{~mm} / \mathrm{d}$ (cohort 3 of 2012). Growth rates also differed across years for old larvae (ANCOVA: $F_{8,53}=10.24, P<0.01$ ). The growth rates of old larvae were generally lower in 2006, 2008, and 2010 than in 2004, 2007, 2009, 2011, and 2012 (no old larvae were collected in 2005). Thus, across both larval age-classes growth rates were slower in 2008 and 2010 than in all of the other years examined.

The most supported model used to predict young larval Yellow Perch growth included temperature and hatch date (Table 2). Both variables were positively related to young larval growth rates (Figure 2). Hatch date alone also provided substantial support for explaining growth rates of young larvae (Table 2). Old larval Yellow Perch growth rates were most related to temperature, postlarval age-0 Yellow Perch density, and preferred zooplankton biomass (Table 3). Interestingly, larval growth rates were positively related to Yellow Perch postlarval age-0 densities and negatively related to available preferred zooplankton biomass (Figure 3). However, the growth rates of old larvae were positively related to water temperature. Other models evaluated received minimal support for explaining patterns in old larvae growth (excluding 2005).

Table 2. Akaike information criterion rankings of post hoc models to explain the growth of young (5-14 d old) larval Yellow Perch from Pelican Lake during 20042012 ( $N=20$ cohorts). Results include the number of parameters $(K)$, the Akaike criterion corrected for small-sample bias ( $\mathrm{AIC}_{c}$ ), the differences in $\mathrm{AIC}_{c}$ from that of the best model $\left(\Delta_{i}\right)$, Akaike weights $\left(w_{i}\right)$, and the proportion of variance explained $\left(r^{2}\right)$. Abbreviations for the independent variables are as follows: TP $=$ water temperature, YEPL = larval Yellow Perch density, PZP = preferred zooplankton biomass, and $\mathrm{HD}=$ hatch date.

\begin{tabular}{lrrrrr} 
Model & $K$ & $\mathrm{AIC}_{c}$ & $\Delta_{i}$ & $w_{i}$ & $r^{2}$ \\
\hline TP, HD & 4 & -39.31 & 0.00 & 0.39 & 76.7 \\
HD & 3 & -37.44 & 1.87 & 0.15 & 58.3 \\
YEPL, PZP & 4 & -36.88 & 2.43 & 0.12 & 69.1 \\
TP, YEPL, HD & 5 & -35.84 & 3.47 & 0.07 & 77.0 \\
YEPL & 3 & -35.82 & 3.49 & 0.07 & 49.8 \\
YEPL, HD & 4 & -35.27 & 4.04 & 0.05 & 62.8 \\
TP, YEPL, PZP & 5 & -34.64 & 4.67 & 0.04 & 73.7 \\
PZP, HD & 4 & -34.50 & 4.81 & 0.04 & 59.4 \\
YEPL, PZP, HD & 5 & -33.60 & 5.71 & 0.02 & 70.3 \\
TP, YEPL, PZP, HD & 6 & -33.06 & 6.25 & 0.02 & 80.4 \\
TP, YPL & 4 & -33.05 & 6.26 & 0.02 & 52.0 \\
TP & 3 & -31.59 & 7.72 & 0.01 & 18.2 \\
PZP & 3 & -31.03 & 8.28 & 0.01 & 12.8 \\
TP, PZP & 4 & -30.75 & 8.56 & 0.01 & 37.4
\end{tabular}




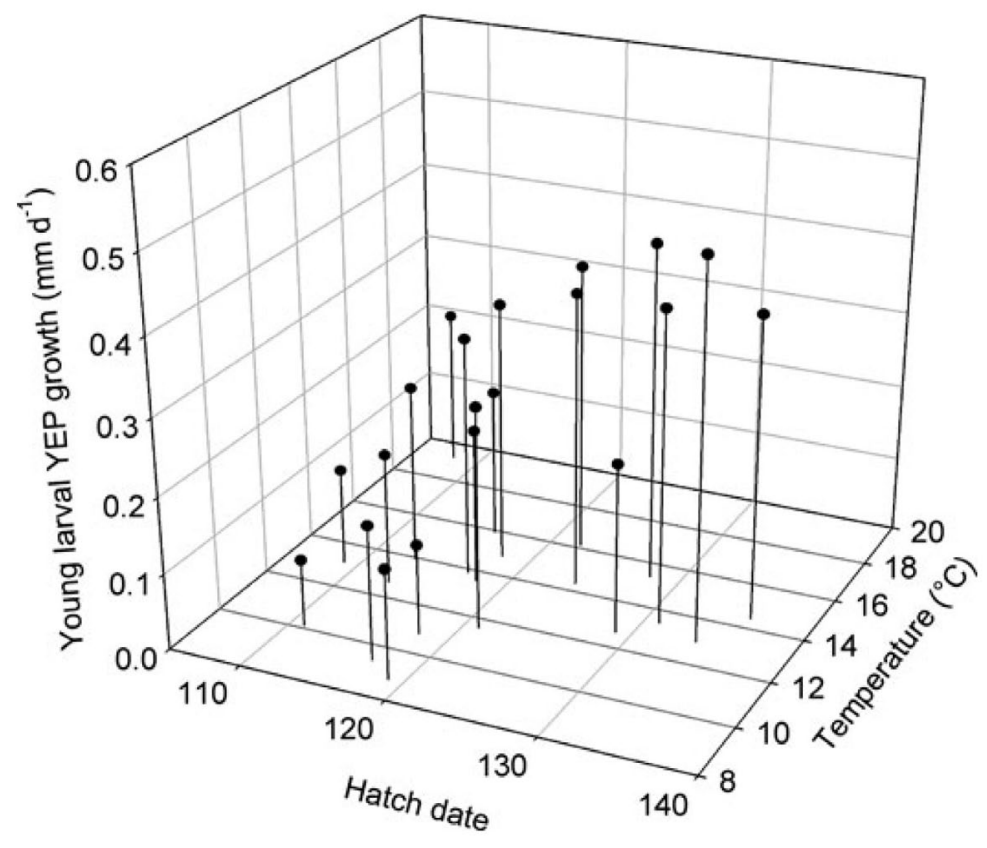

Figure 2. Three-dimensional graph depicting the relationships among temperature, hatch date (day of the year), and growth of young (5-14 $\mathrm{d}$ old) larval Yellow Perch (YEP).

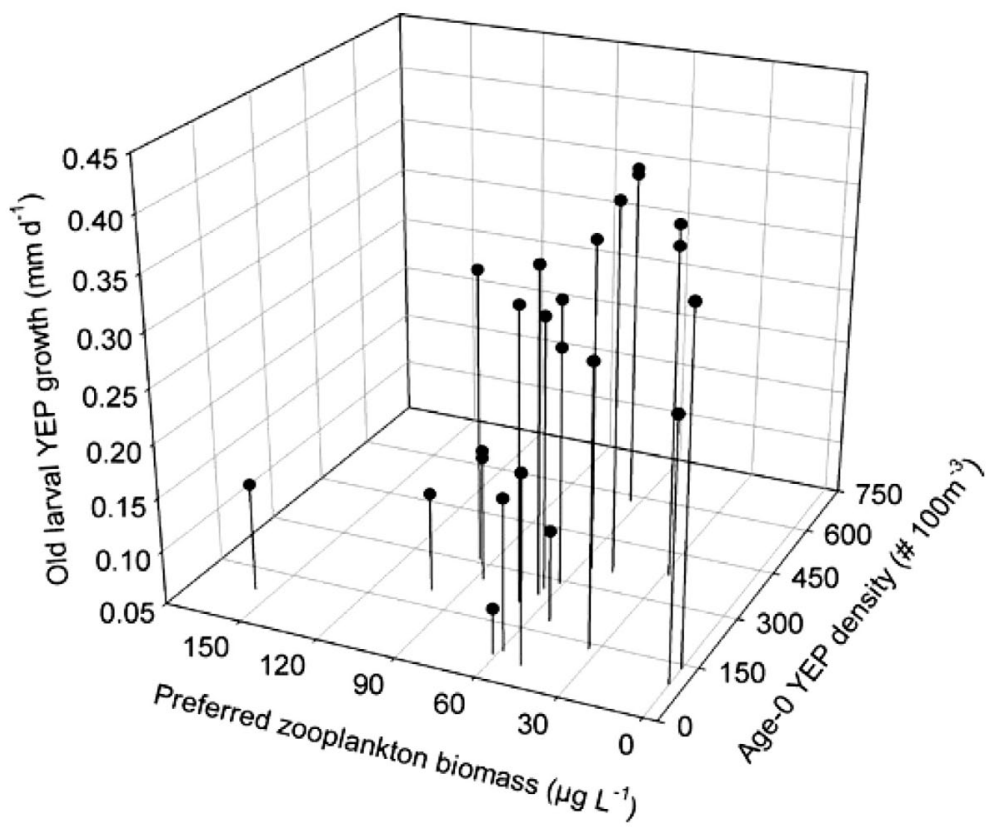

Figure 3. Three-dimensional graph depicting the relationships among preferred zooplankton biomass, postlarval age-0 Yellow Perch (YEP) density, and old (15-24 d old) larval Yellow Perch growth. 
Table 3. Akaike information criterion rankings of post hoc models to explain the growth of old (15-24 d old) larval Yellow Perch from Pelican Lake during 2004-2012 $(N=23$ cohorts). See Table 2 for additional information.

\begin{tabular}{lrrrrr} 
Model & $K$ & $\mathrm{AlC}_{c}$ & $\Delta_{i}$ & $w_{i}$ & $r^{2}$ \\
\hline TP, YEPA, PZP & 5 & -54.95 & 0.00 & 0.77 & 87.5 \\
TP, YEPA, PZP, HD & 6 & -51.69 & 3.26 & 0.15 & 88.1 \\
TP, HD & 4 & -47.93 & 7.03 & 0.02 & 64.9 \\
YEPA, PZP & 4 & -46.79 & 8.16 & 0.01 & 60.6 \\
TP, PZP & 4 & -46.27 & 8.68 & 0.01 & 58.5 \\
TP, YEPA & 4 & -45.47 & 9.48 & 0.01 & 55.1 \\
HD & 3 & -45.20 & 9.75 & 0.01 & 37.9 \\
YEPA & 3 & -45.18 & 9.78 & 0.01 & 37.8 \\
TP, YEPA, HD & 5 & -45.05 & 9.91 & 0.01 & 66.3 \\
PZP, HD & 4 & -43.71 & 11.24 & 0.00 & 46.4 \\
YEPA, PZP, HD & 5 & -43.49 & 11.46 & 0.00 & 60.6 \\
YEPA, HD & 4 & -43.21 & 11.75 & 0.00 & 43.6 \\
TP & 3 & -43.15 & 11.80 & 0.00 & 23.8 \\
PZP & 3 & -43.13 & 11.82 & 0.00 & 23.6
\end{tabular}

\section{Mortality Rate}

Mortality ranged from 0.15 (2007) to 0.52 (2006) across all years except 2005, when Yellow Perch larvae were only collected during one sampling event and at very low density (i.e., <6/100 $\mathrm{m}^{3}$; Jolley et al. 2010), precluding the estimation of mortality. Mortality differed across years for larvae in Pelican Lake (ANCOVA: $F_{8,41}=24.26, P<0.01$; Figure 4). Overall, mortality for larval Yellow Perch was greater in 2006 than in all of the other years examined. In addition, mortality experienced during 2010 was greater than in 2007, 2008, 2009, 2011, and 2012. Among all models evaluated, total available zooplankton biomass, followed by water temperature, provided the most support to explain larval mortality patterns in Pelican Lake (Table 4). Larval mortality was inversely related to total available zooplankton biomass and water temperature (Figure 5).

\section{Discussion}

The growth and survival of larval Yellow Perch in Pelican Lake appear to be primarily regulated by temperature, hatch date, and prey availability. We found many similar relationships in previous studies, despite inherent differences in lake size and morphology (e.g., Laurentian Great Lakes, Oneida Lake, South 
Table 4. Akaike information criterion rankings of post hoc models to explain the mortality of larval Yellow Perch (young and old classes combined; $N=8$ ) from Pelican Lake during 2004-2012 (2005 omitted due to low sample size and resulting lack of mortality estimate). See Table 2 for additional information.

\begin{tabular}{lrrrrr} 
Model & $K$ & $\mathrm{AIC}_{c}$ & $\Delta_{i}$ & $w_{i}$ & $r^{2}$ \\
\hline TZP & 3 & -6.08 & 0.00 & 0.46 & 50.2 \\
TP & 3 & -4.73 & 1.34 & 0.23 & 26.7 \\
GR & 3 & -3.84 & 2.23 & 0.15 & 5.3 \\
YEPL & 3 & -3.66 & 2.42 & 0.14 & 0.0 \\
TP, TZP & 4 & 2.86 & 8.94 & 0.01 & 55.5 \\
YEPL, TZP & 4 & 3.17 & 9.24 & 0.00 & 51.4 \\
TZP, GR & 4 & 3.25 & 9.33 & 0.00 & 50.2 \\
TP, GR & 4 & 4.05 & 10.12 & 0.00 & 37.5 \\
TP, YEPL & 4 & 4.56 & 10.64 & 0.00 & 27.4 \\
YEPL, GR & 4 & 5.15 & 11.23 & 0.00 & 14.1 \\
TP, YEPL, TZP & 5 & 21.38 & 27.46 & 0.00 & 57.3 \\
YEPL, TZP, GR & 5 & 21.64 & 27.71 & 0.00 & 54.1 \\
TP, YEPL, GR & 5 & 22.20 & 28.27 & 0.00 & 46.1 \\
TP, YEPL, TZP, GR & 6 & 77.38 & 83.46 & 0.00 & 57.4
\end{tabular}

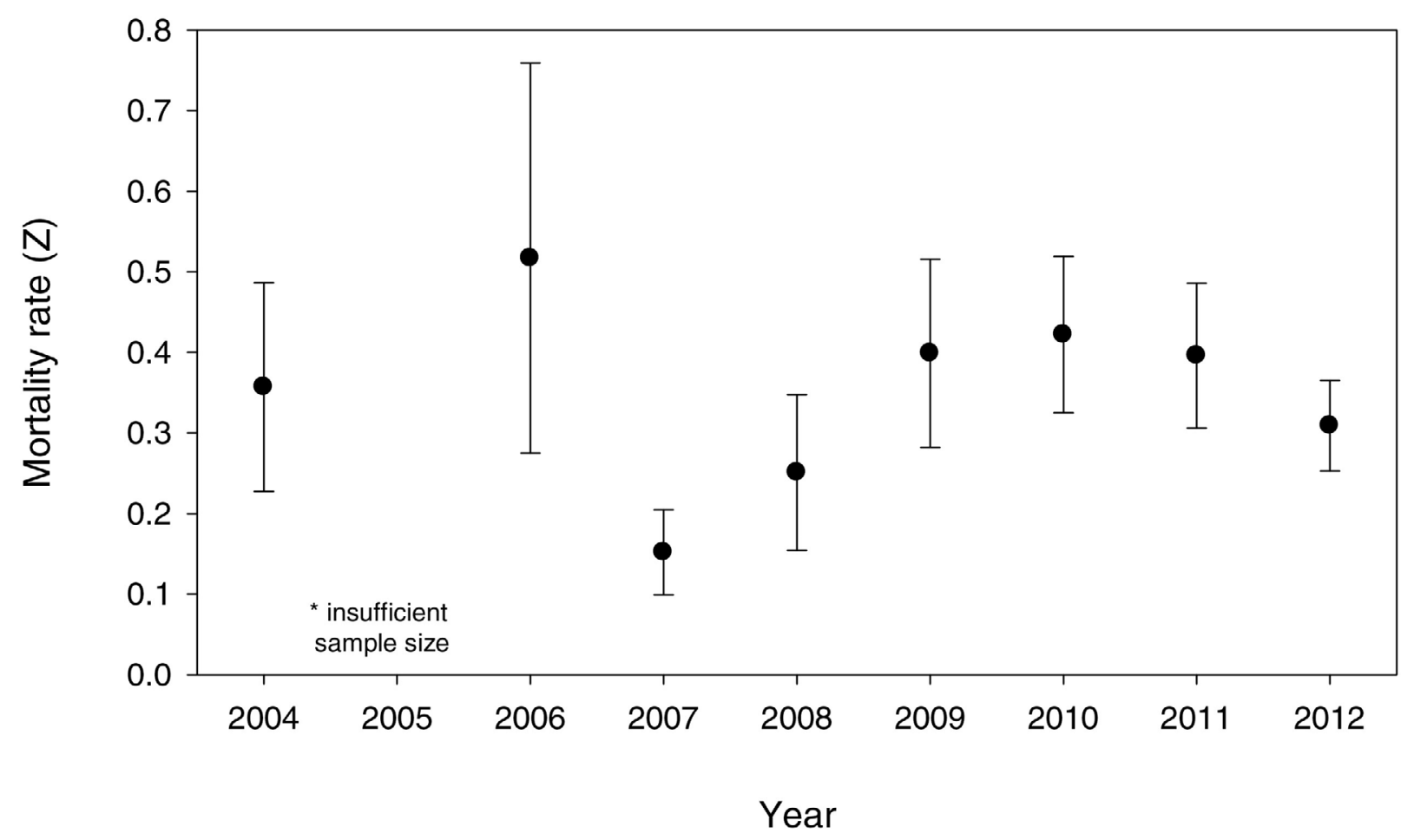

Figure 4. Mean larval Yellow Perch mortality rates $(Z)$ for young and old larvae combined during 2004 through 2012 (except 2005, when the sample size was insufficient to allow calculation of a mortality rate). Error bars represent SEs. 


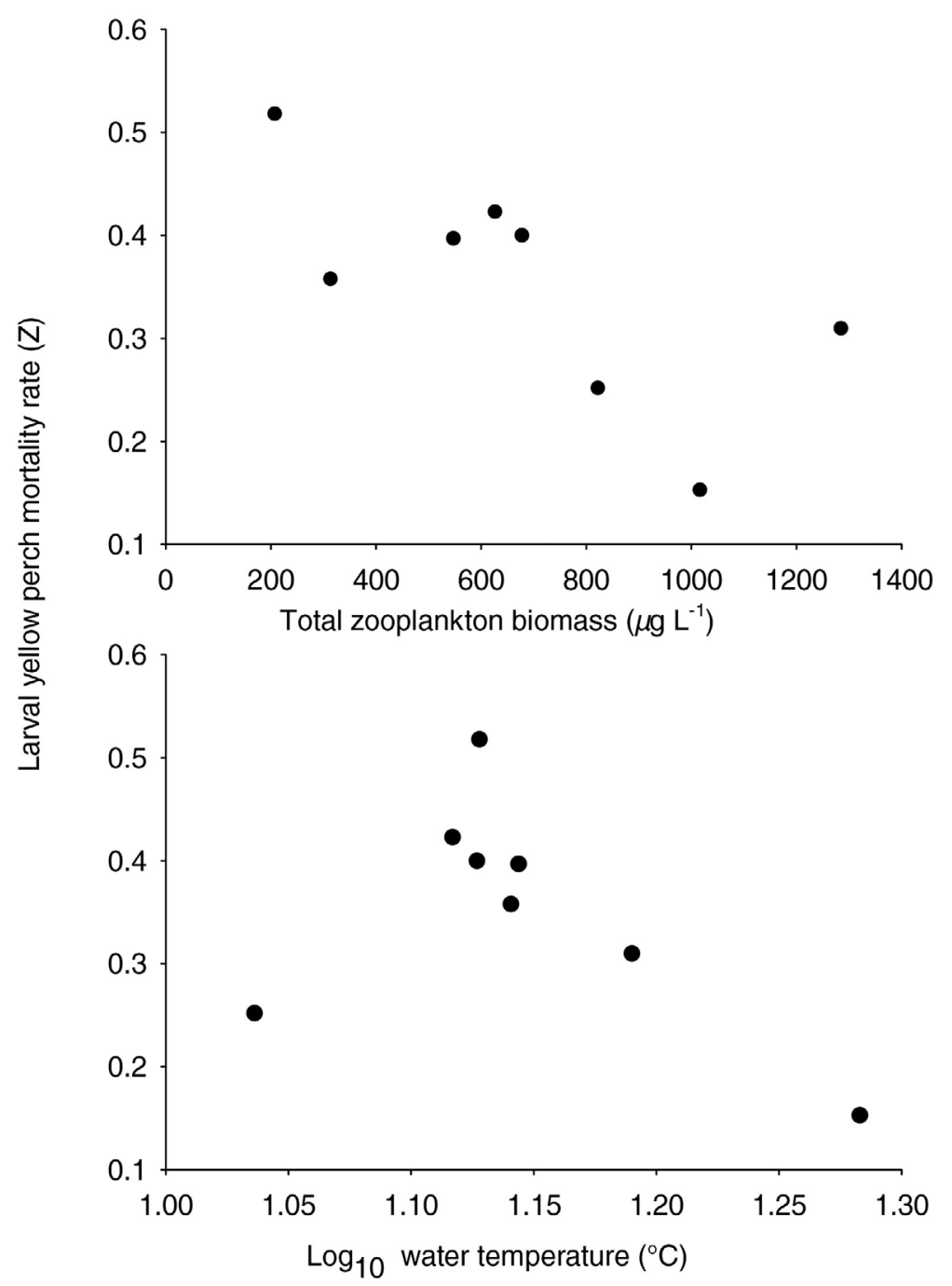

Figure 5. Larval Yellow Perch mortality rates $(Z)$ for young and old larvae combined as functions of total zooplankton biomass (top panel) and log 10 transformed mean water temperature (bottom panel) during 2004 through 2012 (except 2005, when the sample size was insufficient to allow calculation of a mortality rate).

Dakota glacial lakes, and Canadian systems). Our results support the existing hypothesis that Yellow Perch recruitment at the young larval stage (i.e., 5-14 $\mathrm{d}$ old) is primarily driven by abiotic factors (i.e., primarily temperature), but our study extends our understanding to potential biotic controls during the old larval stage (i.e., 15-24 d old). Previous research on Yellow Perch recruitment identified potential abiotic factors involved in the recruitment process at the landscape scale, but patterns were not consistent across all systems suggesting that other (biotic) factors may be influential (Pope et al. 1996; Ward et al. 2004).We observed that temperature and hatch date were important to young 
larval growth, while temperature and zooplankton availability were important for old larval growth. Consequently, Yellow Perch larval recruitment is regulated by all three factors that interact across development stages, temperature having the greatest influence (important for growth and mortality), followed by hatch date and zooplankton abundance (Figure 6).

Young larval growth was related to hatch date and water temperature. In many cases, hatch date and water temperature are related. However, we did not find a strong relationship between these two variables in our study most likely because of unpredictable weather patterns that transpire during Yellow Perch spawning. Cold fronts can occur throughout a typical Yellow Perch spawning season (Isermann and Willis 2008; Jolley et al. 2010;VanDeHey et al. 2013). Inconsistences or acute reductions in temperature (i.e., cold fronts) have been implied to adversely influence Yellow Perch growth, survival, behavior, and subsequent recruitment (Clady 1976; Pope et al. 1996; Ward et al. 2004; Longhenry et al. 2010; VanDeHey et al. 2013). Generally, water temperatures will be most optimal for spawning and early larval development later in the spring rather than earlier, as identified in our study. Previous studies have also found temperature to be important during the young larval life stage (Hokanson and Kleiner 1974; Clady 1976; Cucin and Faber 1985). Similar to other studies, we support the hypothesis that initial larval Yellow Perch growth is regulated more by abiotic factors than by biotic factors.

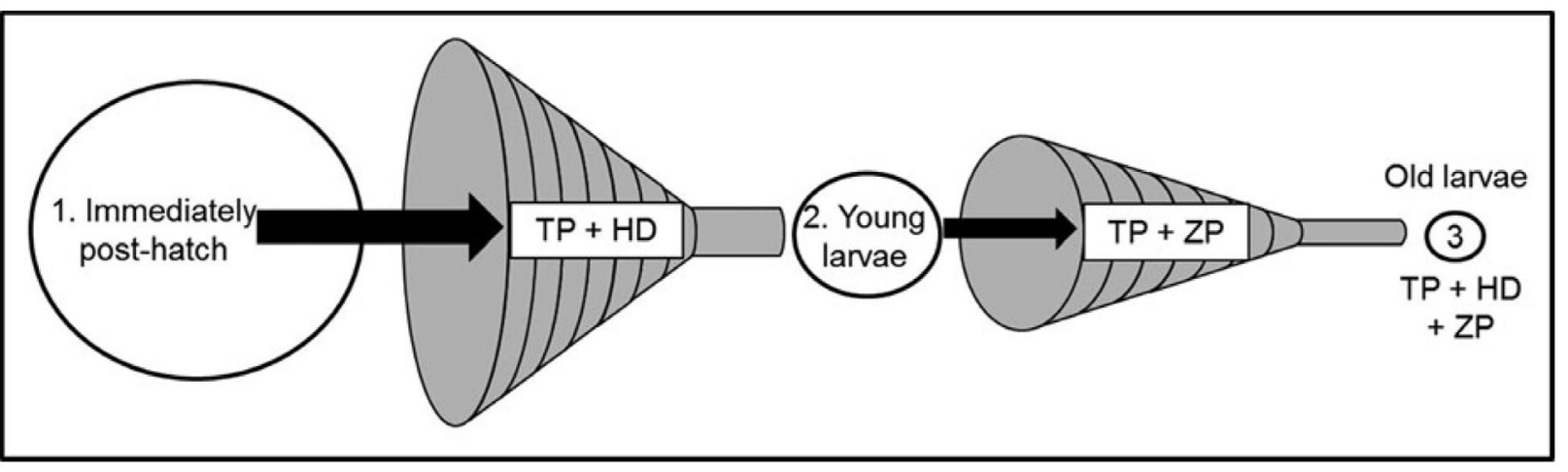

Figure 6. Larval Yellow Perch recruitment bottlenecks and associated mechanisms regulating recruitment at two different life stages (young larvae $=5-14 \mathrm{~d}$ old, old larvae $=15-24 \mathrm{~d}$ old ) in Pelican Lake during 2004-2012. Circles represent larval population sizes (1) immediately posthatch, (2) during the young larval stage, and (3) during the old larval stage. Funnels depict observed recruitment bottlenecks and indicate the primary factors responsible for regulating population abundance during each life stage (TP = water temperature, $\mathrm{HD}=$ hatch date, and $\mathrm{ZP}=$ zooplankton availability). Recruitment to the juvenile life stage reflects the cumulative effects of water temperature, hatch date, and zooplankton availability, with water temperature contributing the most to overall recruitment patterns. 
Yellow Perch growth at the old larval life stage was primarily influenced by temperature, zooplankton abundance, and postlarval age- 0 Yellow Perch ( $\leq 25 \mathrm{~mm} \mathrm{TL}$ ) densities. Larval growth at this life stage was fastest during warmer water temperatures, high postlarval age-0 Yellow Perch densities, and low total zooplankton biomass. We infer that this pattern is indicative of larval Yellow Perch grazing capabilities on available zooplankton (Mills and Forney 1983; Wu and Culver 1994; Kaemingk et al. 2012). Optimal water temperatures experienced during the early larval stage could increase larval survival to the late larval stage and result in higher larval Yellow Perch densities. Higher larval densities that coincide with warmer temperatures could result in increased metabolic demands, subsequently reducing the zooplankton population through direct consumption and ultimately resulting in faster growth rates (Mills and Forney 1981; Post 1990). Several other studies that assessed fish populations and their ability to regulate zooplankton production through direct predation had findings similar to ours (Mills and Forney 1981; Whiteside 1988; Kaemingk et al. 2012). Most previous studies identified temperature as the most influential component to explain patterns in old larval or postlarval age-0 Yellow Perch growth (Mills et al. 1989; Power and van den Heuvel 1999), but we also identified the potential influence of intraspecific competition and food availability (Sanderson et al. 1999; Irwin et al. 2009).

The mortality of larval Yellow Perch in Pelican Lake during 2004-2012 was most strongly linked to the total available zooplankton biomass. During years with low prey availability, larval mortality was high; larval mortality was lowest during years with the greatest amount of zooplankton available. The pattern observed for old larval growth may provide insight relating to the mechanism involved with mortality. High larval Yellow Perch densities may result in reduced zooplankton abundance (via direct consumption) that could translate into starvation or inadequate prey densities required to meet energetic and maintenance metabolic demands. Jolley et al. (2010) identified a temporal match in peak preferred prey abundances and peak larval Yellow Perch abundances, indicating that food availability was adequate during peak larval Yellow Perch abundances in Pelican Lake, as we found in our study.

Larval Yellow Perch may have caused the decline in zooplankton, and although densities were adequate during initial arrival in the limnetic zone and favorable for growth (as observed during the old larval stage), these resources could have declined soon after larval perch arrival. Kaemingk et al. (2011) further explored spatial differences and potential match- mismatches in larval Yellow Perch and prey densities caused by wind events. Little evidence for mismatches was found, but the authors noted that prey densities could be low enough to cause decreased growth and increased mortality for larval fishes during the limnetic life stage. Furthermore, bioenergetics 
modeling paired with diet information suggested that perch were capable of depleting important zooplankton resources via consumption in Pelican Lake during 2004-2010 (Kaemingk et al. 2012). Growth and mortality for larval and juvenile Bluegills Lepomis macrochirus in Pelican Lake were also strongly linked to zooplankton abundance and availability, despite the difficulty in detecting these patterns in field studies (Kaemingk et al. 2014).

In addition to prey availability, we found that water temperature was strongly linked to the mortality patterns of Yellow Perch. Warmer water temperatures experienced during the larval life stage resulted in lower mortality rates. During 2005, only young larval perch were collected on one sampling date that coincided with a cold front (Jolley 2009; VanDeHey et al. 2013), and we documented a subsequent year-class failure. All larvae collected in 2005 had empty stomachs (Jolley et al. 2010), and no individuals were collected in subsequent juvenile sampling. Larval growth is strongly linked to temperature, but mortality could also be just as influenced by temperature. VanDeHey et al. (2013) experimentally demonstrated little evidence for direct Yellow Perch mortality caused by cold fronts but identified a consistent behavioral effect (swimming ceased and larvae settled to the bottom of the tank) that could lead to mortality through starvation or other unfavorable environmental conditions. We conclude that temperature could be the single most important variable involved in the Yellow Perch recruitment process because of its influence on growth during both larval life stages and ultimately on mortality. Temperature has broad implications and effects for both starvation (i.e., productivity) and predation (i.e., growth, gape-limitation, and avoidance). Additionally, hatch date could directly or indirectly influence starvation and predation pressure through variations in temperature regimes. This could also explain why most studies (both broad and in depth) have identified temperature to be important for Yellow Perch growth and survival during the first year of life (Clady 1976; Henderson and Nepszy 1988; Post et al. 1990; Pope et al. 1996; Power and van den Heuvel 1999; Ward et al. 2004; Longhenry et al. 2010).

Our long-term, in-depth study provided additional support for abiotic regulation of Yellow Perch growth and survival at the larval stage, but more importantly, it highlighted the fact that biotic factors may influence the recruitment process if abiotic conditions are favorable for growth and survival. This additional information could assist biologists who need to understand existing, unexplained variation in Yellow Perch year-class strength. Provisionally, it could also help explain interspecific interactions with other fish species that occupy similar trophic niches, such as Bluegills (Kaemingk et al. 2012, 2014; Kaemingk and Willis 2012). If temperature is the primary regulating factor for successful Yellow Perch reproduction and subsequent recruitment, long-term changes in climate may have profound influences on Yellow Perch populations across their native range (Shuter and Post 1990). 
Future studies will undoubtedly need to examine Yellow Perch recruitment using a fine-scale approach to provide the essential information required to gain a more refined understanding of this complex process. Our study identified biotic controls that would be difficult to detect using a broad-scale approach. Therefore, laboratory, in situ experiments or field experiments similar to ours may be required to illuminate complex processes, such as recruitment in fishes.

Acknowledgments - We sincerely thank all the technicians who assisted in the field and laboratory, especially A. Andrews and K. Stahr for the aging component of this study. M. Lindvall and Valentine National Wildlife Refuge provided access to Pelican Lake. Z. Brashears, D. Graham, D. Hartmann, D. Krueger, and the Valentine State Fish Hatchery provided assistance. Thanks to J. Jolley for collecting the first 5 years of this data set. R. Jackson and three anonymous reviewers provided insightful comments that ultimately improved the manuscript. Funding for this project was provided by the Nebraska Game and Parks Commission through Federal Aid in Sport Fish Restoration Project F-118-R.

\section{References}

Auer, N. A. 1982. Identification of larval fishes of the Great Lakes basin with emphasis on the Lake Michigan drainage. Great Lakes Fishery Commission, Special Publication 82-3, Ann Arbor, Michigan.

Bremigan, M. T., J. M. Dettmers, and A. L. Mahan. 2003. Zooplankton selectivity by larval Yellow Perch in Green Bay, Lake Michigan. Journal of Great Lakes Research 29:501-510.

Bunnell, D. B., M. J. González, and R. A. Stein. 2003. Zooplankton biomass enhances growth, but not survival, of first-feeding Pomoxis spp. larvae. Canadian Journal of Fisheries and Aquatic Sciences 60:1314-1323.

Burnham, K. P., and D. R. Anderson. 2002. Model selection and multimodel inference: a practical information-theoretic approach, 2nd edition. Springer, New York.

Chambers, R. C., and E. A. Trippel, editors. 1997. Early life history and recruitment in fish populations. Chapman and Hall, New York.

Clady, M., and B. Hutchinson. 1975. Effect of high winds on eggs of Yellow Perch, Perca flavescens, in Oneida Lake, New York. Transactions of the American Fisheries Society 104:524-525.

Clady, M. D. 1976. Influence of temperature and wind on the survival of early stages of Yellow Perch, Perca flavescens. Journal of the Fisheries Research Board of Canada 33:1887-1893.

Claramunt, R. M., and D. H. Wahl. 2000. The effects of abiotic and biotic factors in determining larval fish growth rates: a comparison across species and reservoirs. Transactions of the American Fisheries Society 129:835- 851. 
Cucin, D., and D. J. Faber. 1985. Early life history studies of Lake Whitefish (Coregonus clupeaformis), Cisco (Coregonus artedii) and Yellow Perch (Perca flavescens) in Lake Opeongo, Ontario. Ontario Ministry of Natural Resources, Ontario Fisheries Technical Report Series 16, Toronto.

Culver, D. A., M. M. Boucherle, D. J. Bean, and J.W. Fletcher. 1985. Biomass of freshwater crustacean zooplankton from length-weight regressions. Canadian Journal of Fisheries and Aquatic Sciences 42:1380-1390.

Cummins, K. W., and J. C. Wuycheck. 1971. Caloric equivalents for investigations in ecological energetics. Internationale Vereinigung für Theoretische und Angewandte Limnologie Verhandlungen 18.

Dumont, H. J., and G. Balvay. 1979. The dry weight estimate of Chaoborus flavicans (Meigen) as a function of length and instars. Hydrobiologia 64:139- 145.

Fulford, R. S., J. A. Rice, T. J. Miller, F. P. Binkowski, J. M. Dettmers, and B. Belonger. 2006. Foraging selectivity by larval Yellow Perch (Perca flavescens): implications for understanding recruitment in small and large lakes. Canadian Journal of Fisheries and Aquatic Sciences 63:28-42.

Graeb, B. D. S., J. M. Dettmers, D. H. Wahl, and C. E. Cáceres. 2004. Fish size and prey availability affect growth, survival, prey selection, and foraging behavior of larval Yellow Perch. Transactions of the American Fisheries Society 133:504-514.

Heidinger, R. C., and T. B. Kayes. 1993. Culture of nonsalmonid freshwater fishes. Pages 216-229 in R. R. Stickney, editor. Advances in fisheries science. CRC Press, Boca Raton, Florida.

Henderson, B. A., and S. J. Nepszy. 1988. Recruitment of Yellow Perch (Perca flavescens) affected by stock size and water temperature in Lakes Erie and St. Clair, 1965-85. Journal of Great Lakes Research 14:205-215.

Hokanson, K. E. F., and C. F. Kleiner. 1974. Effects of constant and rising temperatures on the survival and development rates of embryonic and larval Yellow Perch, Perca flavescens (Mitchill). Pages 437-448 in J. H. S. Blaxster, editor. The early life history of fish. Springer-Verlag, Berlin.

Holland-Bartels, L. E., S. K. Littlejohn, and M. L. Huston. 1990. A guide to the larval fishes of the upper Mississippi River. U.S. Fish and Wildlife Service, LaCrosse, Wisconsin.

Irwin, B. J., L. G. Rudstam, J. R. Jackson, A. J. VanDeValk, J. L. Forney, and D. G. Fitzgerald. 2009. Depensatory mortality, density-dependent growth, and delayed compensation: disentangling the interplay of mortality, growth, and density during early life stages of Yellow Perch. Transactions of the American Fisheries Society 138:99-110.

Isermann, D. A., D. W. Willis, B. G. Blackwell, and D. O. Lucchesi. 2007. Yellow Perch in South Dakota: population variability and predicted effects of creel limit reductions and minimum length limits. North American Journal of Fisheries Management 27:918-931.

Isermann, D. A., and D. W. Willis. 2008. Emergence of larval Yellow Perch, Perca flavescens, in South Dakota lakes: potential implications for recruitment. Fisheries Management and Ecology 15:259-271. 
Jolley, J. C. 2009. Recruitment of Bluegill and Yellow Perch in Nebraska Sandhills lakes: integrating multiple life stages. Doctoral dissertation. South Dakota State University, Brookings.

Jolley, J. C., D. W. Willis, and R. S. Holland. 2010. Match-mismatch regulation for Bluegill and Yellow Perch larvae and their prey in Sandhill lakes. Journal of Fish and Wildlife Management 1:73-85.

Kaemingk, M. A., J. C. Jolley, D. W. Willis, and S. R. Chipps. 2012. Priority effects among young-of-the-year fish: reduced growth of Bluegill sunfish (Lepomis macrochirus) caused by Yellow Perch (Perca flavescens)? Freshwater Biology 57:654-665.

Kaemingk, M. A., J. C. Jolley, D. W. Willis, and B. D. S. Graeb. 2011. Exploring spatial distributions of larval Yellow Perch Perca flavescens, Bluegill Lepomis macrochirus, and their prey in relation to wind. Journal of Fish Biology 78:1132-1151.

Kaemingk, M. A., K. J. Stahr, J. C. Jolley, R. S. Holland, and D. W. Willis. 2014. Evidence for Bluegill spawning plasticity obtained by disentangling complex factors related to recruitment. Canadian Journal of Fisheries and Aquatic Sciences 71:93-105.

Kaemingk, M. A., and D. W. Willis. 2012. Mensurative approach to examine potential interactions between age-0 Yellow Perch (Perca flavescens) and Bluegill (Lepomis macrochirus). Aquatic Ecology 46:353-362.

Kallemeyn, L. W. 1987. Correlations of regulated lake levels and climatic factors with abundance of young-of-the-year Walleye and Yellow Perch in four lakes in Voyageurs National Park. North American Journal of Fisheries Management 7:513-521.

Koonce, J. F., T. B. Bagenal, R. F. Carline, K. E. F. Hokanson, and M. Nagięć. 1977. Factors influencing year-class strength of percids: a summary and a model of temperature effects. Journal of the Fisheries Research Board of Canada 34:1890-1899.

Lind, O. T. 1985. Handbook of common methods in limnology, 2nd edition. Kendall/Hunt Publishing, Dubuque, lowa.

Longhenry, C. M.,M. L. Brown, and T. R. St. Sauver. 2010. Climatological factors influencing Yellow Perch production in semipermanent wetlands. Prairie Naturalist 42:38-44.

Lynch, M., L. J. Weider, and W. Lampert. 1986. Measurement of the carbon balance in Daphnia. Limnology and Oceanography 31:17-33.

McCarraher, D. B. 1964. Limnology of carbonate-bicarbonate lakes in Nebraska. Nebraska Game and Parks Commission, White Papers, Conference Presentations, and Manuscripts, Paper 8, Lincoln.

McCauley, E., and J. Kalff. 1981. Empirical relationships between phytoplankton and zooplankton biomass in lakes. Canadian Journal of Fisheries and Aquatic Sciences 38:458-463.

Mills, E. L., and J. L. Forney. 1981. Energetics, food consumption, and growth of young Yellow Perch in Oneida Lake, New York. Transactions of the American Fisheries Society 110:479-488.

Mills, E. L., and J. L. Forney. 1983. Impact on Daphnia pulex of predation by young Yellow Perch in Oneida Lake, New York. Transactions of the American Fisheries Society 112:154-161. 
Mills, E. L., R. Sherman, and D. S. Robson. 1989. Effect of zooplankton abundance and body size on growth of age-0 Yellow Perch (Perca flavescens) in Oneida Lake, New York, 1975-86. Canadian Journal of Fisheries and Aquatic Sciences 46:880-886.

Newsome, G. E., and S. K. Aalto. 1987. An egg mass census method for tracking fluctuations in Yellow Perch (Perca flavescens) populations. Canadian Journal of Fisheries and Aquatic Sciences 44:1221-1232.

Paukert, C. P., D. W. Willis, and R. S. Holland. 2002. Sample size requirements for in situ vegetation and substrate classifications in shallow, natural Nebraska lakes. North American Journal of Fisheries Management 22:1329- 1333.

Pope, K. L., D. W. Willis, and D. O. Lucchesi. 1996. Differential relations of age-0 Black Crappie and Yellow Perch to climatological variables in a natural lake. Journal of Freshwater Ecology 11:345-350.

Post, J. R. 1990. Metabolic allometry of larval and juvenile Yellow Perch (Perca flavescens): in situ estimates and bioenergetic models. Canadian Journal of Fisheries and Aquatic Sciences 47:554-560.

Post, J. R., and A. B. Prankevicius. 1987. Size-selective mortality in young-of-theyear Yellow Perch (Perca flavescens): evidence from otolith microstructure. Canadian Journal of Fisheries and Aquatic Sciences 44:1840- 1847.

Power, M., and M. R. van den Heuvel. 1999. Age-0 Yellow Perch growth and its relationship to temperature. Transactions of the American Fisheries Society 128:687-700.

Powles, P. M., and S. M. Warlen. 1988. Estimation of hatch periods for Yellow Perch, based on otolith readings from juveniles (age-0). Transactions of the American Fisheries Society 5:60-67.

Rabeni, C. 1996. Invertebrates. Pages 335-352 in B. R. Murphy and D. W. Willis, editors. Fisheries techniques, 2nd edition. American Fisheries Society, Bethesda, Maryland.

Rice, J. A., L. B. Crowder, and F. P. Binkowski. 1987. Evaluating potential sources of mortality for larval bloater (Coregonus hoyi): starvation and vulnerability to predation. Canadian Journal of Fisheries and Aquatic Sciences 44:467-472.

Ricker, W. E. 1975. Computation and interpretation of biological statistics of fish populations. Fisheries Research Board of Canada Bulletin 191.

Sanderson, B. L., T. R. Hrabik, J. J. Magnuson, and D. M. Post. 1999. Cyclic dynamics of a Yellow Perch (Perca flavescens) population in an oligotrophic lake: evidence for the role of intraspecific interactions. Canadian Journal of Fisheries and Aquatic Sciences 56:1534-1542.

Santucci, V. J., and D. H. Wahl. 2003. The effects of growth, predation, and firstwinter mortality on recruitment of Bluegill cohorts. Transactions of the American Fisheries Society 132:346-360. SAS Institute. 2003. SAS online document, version 9. SAS Institute, Cary, North Carolina.

Schael, D. M., L. G. Rudstam, and J. R. Post. 1991. Gape limitation and prey selection in larval Yellow Perch (Perca flavescens), Freshwater Drum (Aplodinotus grunniens), and Black Crappie (Pomoxis nigromaculatus). Canadian Journal of Fisheries and Aquatic Sciences 48:1919-1925. 
Shuter, B. J., and J. R. Post. 1990. Climate, population viability, and the zoogeography of temperate fishes. Transactions of the American Fisheries Society 119:314-336.

VanDeHey, J. A., M. A. Kaemingk, A. C. Jansen, B. D. S. Graeb, D. J. Dembkowski, and D. W. Willis. 2013. Effects of simulated cold fronts on the survival and behaviour of Yellow Perch Perca flavescens yolk-sac fry. Journal of Applied Ichthyology 29:364-367.

Ward, M. J., M. R. Anderson, S. J. Fisher, D. A. Isermann, Q. E. Phelps, and D. W. Willis. 2004. Relations between climatological variables and larval Yellow Perch abundance in eastern South Dakota glacial lakes. Journal of Freshwater Ecology 19:213-218.

Whiteside, M. 1988. 0+ fish as major factors affecting abundance patterns of littoral zooplankton. Internationale Vereinigung für theoretische und angewandte Limnologie Verhandlungen 23:1710-1714.

Wu, L., and D. A. Culver. 1994. Daphnia population dynamics in western Lake Erie: regulation by food limitation and Yellow Perch predation. Journal of Great Lakes Research 20:537-545. 